\title{
PDGF-CC induces tissue factor expression: role of PDGF receptor alpha/beta
}

Gebhard, C ; Akhmedov, A ; Mocharla, P ; Angstenberger, J ; Sahbai, S ; Camici, G G ; Lüscher, T F ; Tanner, F C

\begin{abstract}
Tissue factor (TF) is the principal trigger of the coagulation cascade and involved in arterial thrombus formation. Platelet-derived growth factor CC (PDGF-CC) is a recently discovered member of the PDGF family released upon platelet activation. This study assesses the impact of PDGF-CC on TF expression in human cells. PDGF-CC concentration-dependently induced TF expression by 2.5fold in THP-1 cells, by 2.0-fold in human peripheral blood monocytes, by 1.4-fold in vascular smooth muscle cells, and by 2.6-fold in microvascular endothelial cells, but did not affect TF expression in aortic endothelial cells. A similar pattern was observed with PDGF-BB. In contrast, PDGF-AA did not alter TF expression in THP-1 cells. TF whole cell activity was induced following stimulation with PDGF-BB and PDGF-CC in THP-1 cells. Real-time polymerase chain reaction revealed that PDGF-CC induced TF mRNA. PDGF-CC transiently activated p42/44 MAP kinase [extracellular signal-regulated kinase (ERK)], while phosphorylation of the MAP kinases c-Jun NH(2)-terminal kinase (JNK) and p38 remained unaffected. PD98059, a specific inhibitor of ERK phosphorylation, but not the p38 inhibitor SB203580 or the JNK inhibitor SP600125 prevented PDGF-CC induced TF expression in a concentration-dependent manner. The effect of PDGF-CC was antagonized by both PDGF receptor alpha and PDGF receptor beta neutralizing antibodies; in contrast, PDGF-BB was only inhibited by PDGF receptor beta blocking antibody. PDGF receptor alpha and PDGF receptor beta inhibition prevented PDGF-CC-induced ERK phosphorylation. PDGF-CC induces TF expression via activation of alpha/beta receptor heterodimers and an ERK-dependent signal transduction pathway.
\end{abstract}

DOI: https://doi.org/10.1007/s00395-009-0060-0

Posted at the Zurich Open Repository and Archive, University of Zurich

ZORA URL: https://doi.org/10.5167/uzh-29225

Journal Article

Published Version

Originally published at:

Gebhard, C; Akhmedov, A; Mocharla, P; Angstenberger, J; Sahbai, S; Camici, G G; Lüscher, T F; Tanner, F C (2009). PDGF-CC induces tissue factor expression: role of PDGF receptor alpha/beta. Basic Research in Cardiology, 105(3):349-356.

DOI: https://doi.org/10.1007/s00395-009-0060-0 


\title{
PDGF-CC induces tissue factor expression: role of PDGF receptor $\alpha / \beta$
}

\author{
Cathérine Gebhard · Alexander Akhmedov $\cdot$ Pavani Mocharla \\ Jonas Angstenberger · Saba Sahbai - Giovanni G. Camici • \\ Thomas F. Lüscher $\cdot$ Felix C. Tanner
}

Received: 22 December 2008/Revised: 17 July 2009/Accepted: 1 September 2009/Published online: 1 October 2009

(c) Springer-Verlag 2009

\begin{abstract}
Tissue factor (TF) is the principal trigger of the coagulation cascade and involved in arterial thrombus formation. Platelet-derived growth factor CC (PDGF-CC) is a recently discovered member of the PDGF family released upon platelet activation. This study assesses the impact of PDGF-CC on TF expression in human cells. PDGF-CC concentration-dependently induced TF expression by 2.5 -fold in THP-1 cells, by 2.0 -fold in human peripheral blood monocytes, by 1.4-fold in vascular smooth muscle cells, and by 2.6 -fold in microvascular endothelial cells, but did not affect TF expression in aortic endothelial cells. A similar pattern was observed with PDGF-BB. In contrast, PDGF-AA did not alter TF expression in THP-1 cells. TF whole cell activity was induced following stimulation with PDGF-BB and PDGF-CC in THP-1 cells. Real-time polymerase chain reaction revealed that PDGF$\mathrm{CC}$ induced TF mRNA. PDGF-CC transiently activated p42/44 MAP kinase [extracellular signal-regulated kinase (ERK)], while phosphorylation of the MAP kinases c-Jun
\end{abstract}

C. Gebhard - A. Akhmedov - P. Mocharla - J. Angstenberger .

S. Sahbai - G. G. Camici - T. F. Lüscher - F. C. Tanner

Cardiovascular Research, Physiology Institute,

University of Zurich, Zurich, Switzerland

C. Gebhard - A. Akhmedov - P. Mocharla - J. Angstenberger .

S. Sahbai - G. G. Camici - T. F. Lüscher · F. C. Tanner

Center for Integrative Human Physiology, University of Zurich,

Zurich, Switzerland

C. Gebhard · T. F. Lüscher · F. C. Tanner $(\square)$

Cardiology, Cardiovascular Center, University Hospital Zurich,

Winterthurerstrasse 190, 8057 Zurich, Switzerland

e-mail: felix.tanner@access.uzh.ch
$\mathrm{NH}_{2}$-terminal kinase (JNK) and p38 remained unaffected. PD98059, a specific inhibitor of ERK phosphorylation, but not the p38 inhibitor SB203580 or the JNK inhibitor SP600125 prevented PDGF-CC induced TF expression in a concentration-dependent manner. The effect of PDGF-CC was antagonized by both PDGF receptor $\alpha$ and PDGF receptor $\beta$ neutralizing antibodies; in contrast, PDGF-BB was only inhibited by PDGF receptor $\beta$ blocking antibody. PDGF receptor $\alpha$ and PDGF receptor $\beta$ inhibition prevented PDGF-CC-induced ERK phosphorylation. PDGF$\mathrm{CC}$ induces TF expression via activation of $\alpha / \beta$ receptor heterodimers and an ERK-dependent signal transduction pathway.

Keywords Tissue factor - PDGF - Monocytes · Microvascular endothelial cells · Arterial thrombosis

\section{Introduction}

Platelet-derived growth factor (PDGF) was originally identified as a mitogen for fibroblasts and vascular smooth muscle cells and has been linked to a number of human diseases. The PDGF family consists of at least three members signaling through the $\alpha$ - and/or $\beta$-PDGF receptor (PDGFR) tyrosine kinases. PDGF-CC, a recently discovered family member, is detectable at a high level in platelets, vascular smooth muscle cells, and microvascular endothelial cells [7, 30], and has been characterized as a potent angiogenic mediator.

Tissue factor (TF), a 47-kDa transmembrane glycoprotein, is the main trigger of blood coagulation and plays a central role in thrombus formation [29]. Various mediators can induce TF in monocytes, endothelial cells, and vascular smooth muscle cells [29]. PDGF-BB, a well-characterized 
member of the PDGF family, induces TF expression in monocytes and vascular smooth muscle cells [6, 18, 25]. However, PDGF-BB constitutes only about $7 \%$ of total PDGF activity in human serum, and the relative contribution of different PDGF isoforms to thrombus formation and acute vascular syndromes is unknown [3]. Moreover, PDGF-CC is released upon platelet activation and can be cleaved to its active form by plasmin or tissue-type plasminogen activator $[7,10,20]$, suggesting a possible role at sites of thrombosis. In spite of these insights, potential prothrombotic properties of PDGF-CC remain poorly characterized.

Hence, this study examines the impact of PDGF-CC on TF expression in human cells.

\section{Materials and methods}

Cell culture

Human aortic endothelial cells (HAEC; Clonetics, Allschwil, Switzerland) were cultured as described [11]. Human microvascular endothelial cells (HMVEC; Clonetics) were grown in EGM-MV growth medium (Clonetics) containing $10 \%$ FCS, THP-1 cells (LGC Promochem, Molsheim, France) in RPMI 1640 containing $25 \mathrm{mmol} / \mathrm{L}$ HEPES buffer and 10\% FCS, and human aortic vascular smooth muscle cells (HAVSMC) in DMEM containing $10 \%$ FCS. Peripheral blood mononuclear cells were isolated from healthy subjects by density centrifugation in vacutainer cell preparation tubes with sodium heparin (Becton-Dickinson, Franklin Lakes, NJ) and further purified by magnetic-activated cell separation sorting with anti-human CD14 antibody (Miltenyi Biotec, Cologne, Germany) conjugated to magnetic beads. Purity was assessed by flow cytometry (FACSCanto, BD, Heidelberg, Germany) using FITC-conjugated anti-human CD14 antibody (Miltenyi Biotec). Monocytes were cultured in RPMI 1640 containing $25 \mathrm{mmol} / \mathrm{L}$ HEPES buffer and 10\% FCS. Human monocytes and THP-1 cells were rendered quiescent in starvation medium (0.5\% FCS) for 18 and $24 \mathrm{~h}$, respectively. Adhering cells were grown to confluence in $3 \mathrm{~cm}$ dishes and rendered quiescent in starvation medium for $24 \mathrm{~h}$ before stimulation with PDGF-AA, PDGF-BB, or PDGF-CC (all from R\&D, Abingdom, UK) for $5 \mathrm{~h}$. SB203580 (Sigma, Buchs, Switzerland), PD98059 (Cell Signaling, Danvers, MA), and SP600125 (Calbiochem, Nottingham, UK) were added $60 \mathrm{~min}$ before stimulation. Antibodies blocking PDGF receptor $\alpha$ and PDGF receptor $\beta$ (MAB 322 and AF 385; R\&D Systems, Abingdon, UK) were added at 5 and $1.25 \mu \mathrm{g} / \mathrm{mL}$, respectively. Cytotoxicity was assessed with a colorimetric assay to detect lactate dehydrogenase release (Roche, Basel, Switzerland) [28].
Western blot

Protein expression was determined by Western blot analysis as described [27]. Cells were lysed in $50 \mathrm{mmol} / \mathrm{L}$ Tris buffer; $40 \mu \mathrm{g}$ samples were loaded, separated by $10 \%$ sodium dodecyl sulfate polyacrylamide gel electrophoresis, and transferred to a polyvinylidene difluoride membrane (Millipore, Volketswil, Switzerland) by semidry transfer. Antibodies against human TF (American Diagnostica, Stamford, CA) were used at 1:2,000 dilution. Antibodies against phosphorylated p38 MAP kinase (p38), phosphorylated p44/42 MAP kinase [extracellular signal-regulated kinase (ERK)], and phosphorylated c-Jun NH2-terminal kinase (JNK; all from Cell Signaling) were used at 1:1,000, 1:5,000, and 1:1,000 dilutions, respectively. Antibodies against total p38, ERK, and JNK (all from Cell Signaling) were used at 1:2,000, 1:10,000, and 1:1,000 dilutions, respectively. All blots were normalized to $\alpha$-tubulin (aT) expression (1:20,000 dilution, Sigma) [27].

\section{TF activity}

Tissue factor activity was analyzed in THP-1 whole cell lysates using a colorimetric assay (American Diagnostica). TF/FVIIa converted factor $\mathrm{X}$ to factor $\mathrm{Xa}$, which was measured by its ability to metabolize a chromogenic substrate. A standard curve with lipidated human TF was performed to assure that measurements were taken in the linear range of detection.

\section{Real-time PCR}

All real-time PCR experiments were performed in triplicate using the SYBR Green JumpStart kit (Sigma) in an MX3000P PCR cycler (Stratagene, Amsterdam, The Netherlands). Each reaction $(25 \mu \mathrm{L})$ contained $2 \mu \mathrm{L}$ cDNA, 1 pmol of each primer, $0.25 \mu \mathrm{L}$ of internal reference dye, and $12.5 \mu \mathrm{L}$ of JumpStart Taq ReadyMix (containing buffer, dNTPs, stabilizers, SYBR Green, Taq polymerase, and JumpStart Taq antibody). The following primers were used: human tissue factor $(F 3)$ : sense primer: 5'-TCCCCAGAGTTCACACCTTACC-3' (bases 508-529 of $F 3$ cDNA; NCBI no. NM 001993), antisense primer: 5'-TGACCACAAATACCACAGCTCC-3' (bases 892-913 of $F 3$ cDNA; NCBI no. NM 001993); human L28: sense primer: 5'-GCATCTGCAATGGATGGT-3', antisense primer: 5'-TGTTCTTGCGGATCATGTGT- $3^{\prime}$. The amplification program consisted of 1 cycle at $95^{\circ} \mathrm{C}$ for $10 \mathrm{~min}$ followed by 40 cycles with a denaturing phase at $95^{\circ} \mathrm{C}$ for $30 \mathrm{~s}$, an annealing phase at $60^{\circ} \mathrm{C}$ for $1 \mathrm{~min}$, and an elongation phase at $72^{\circ} \mathrm{C}$ for $1 \mathrm{~min}$. PCR products were analyzed on an ethidium bromide stained $1 \%$ agarose gel, and a melting curve analysis was performed after amplification 
to verify the accuracy of the amplicon. In each real-time PCR run for $F 3$ and L28, a calibration curve was included that was generated from serial dilutions of the respective purified amplicon [27].

\section{Statistics}

Data are presented as mean \pm SEM. Statistical analysis was performed by 2-tailed unpaired Student's $t$ test or ANOVA as appropriate. A probability value of $<0.05$ was considered significant.

\section{Results}

PDGF-CC induces TF protein expression and activity

THP-1 cells were stimulated with PDGF-CC, PDGF-BB, or PDGF-AA $(0.1-10 \mathrm{ng} / \mathrm{mL})$ for $5 \mathrm{~h}$. PDGF-CC induced TF expression in a concentration-dependent manner with a maximal effect occurring at $10 \mathrm{ng} / \mathrm{mL}$ and resulting in a 2.5-fold induction as compared to unstimulated cells
( $n=9, P<0.05$; Fig. 1a). Similarly, PDGF-BB enhanced TF expression by 2.1 -fold as compared to control $(n=6$, $P<0.05$; Fig. 1b). In contrast, PDGF-AA did not affect TF expression $(n=9, P=$ NS; Fig. 1c). The effect of PDGF-CC and PDGF-BB on TF protein expression in THP-1 cells was paralleled by an increased cellular TF activity 2.0-fold and 1.7-fold, respectively, at the maximal concentration ( $n=4, P<0.05$; Fig. $1 \mathrm{~d})$.

Similar to THP-1 cells, PDGF-CC (1-10 ng/mL) induced TF expression in human peripheral blood monocytes by 2.1 -fold ( $n=4, P<0.05$; Fig. $2 \mathrm{a}$ ), in human microvascular endothelial cells by 2.5 -fold $(n=11$, $P<0.05$; Fig. 2 b), and in human aortic vascular smooth muscle cells by 1.3 -fold ( $n=5, P<0.05$; Fig. 2 c). PDGF$\mathrm{BB}(10 \mathrm{ng} / \mathrm{mL})$ induced TF expression in human peripheral blood monocytes by 1.7 -fold ( $n=4, P<0.05$; Fig. 2 a), in microvascular endothelial cells by 1.7 -fold $(n=10$, $P<0.05$; Fig. 2b) and in human aortic vascular smooth muscle cells by 1.4 -fold $(n=5, P<0.05$; Fig. 2 c). In contrast, PDGF-CC and PDGF-BB did not alter TF expression in human aortic endothelial cells $(n=3$, $P=$ NS; Fig. 2d).
Fig. 1 PDGF-CC (a) and PDGF-BB (b), but not PDGFAA (c), induced TF protein expression in THP-1 cells. Values are indicated as percent of control and representative of at least four different experiments; all blots are normalized to $\alpha$-tubulin $(a T)$ expression; $* P<0.05$ versus control. d PDGF-BB and PDGF-CC induced TF whole cell activity in THP-1 cells; $* P<0.05$ versus control
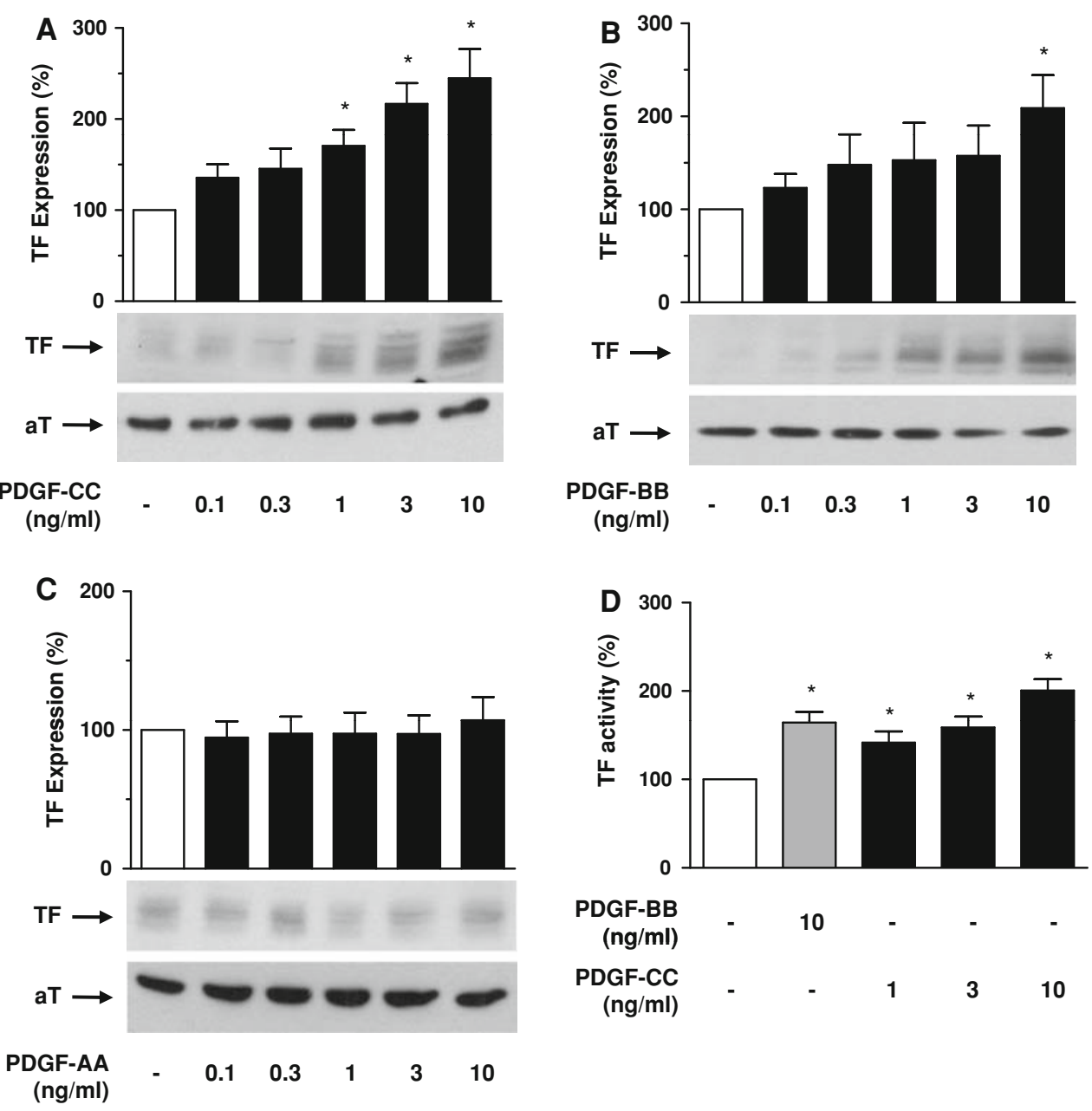
Fig. 2 PDGF-CC-induced TF protein expression in human peripheral blood monocytes (a), human microvascular endothelial cells (b) and human aortic vascular smooth muscle cells (c), but not human aortic endothelial cells (d). PDGF-BB is included as a positive control. Values are indicated as percent of control and representative of at least three different experiments; all blots are normalized to $\alpha$-tubulin ( $a T)$ expression; $* P<0.05$ versus control

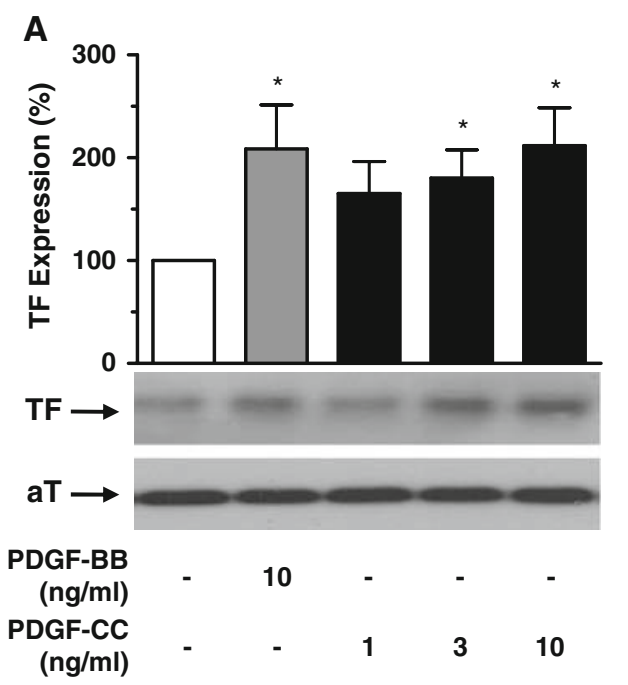

B
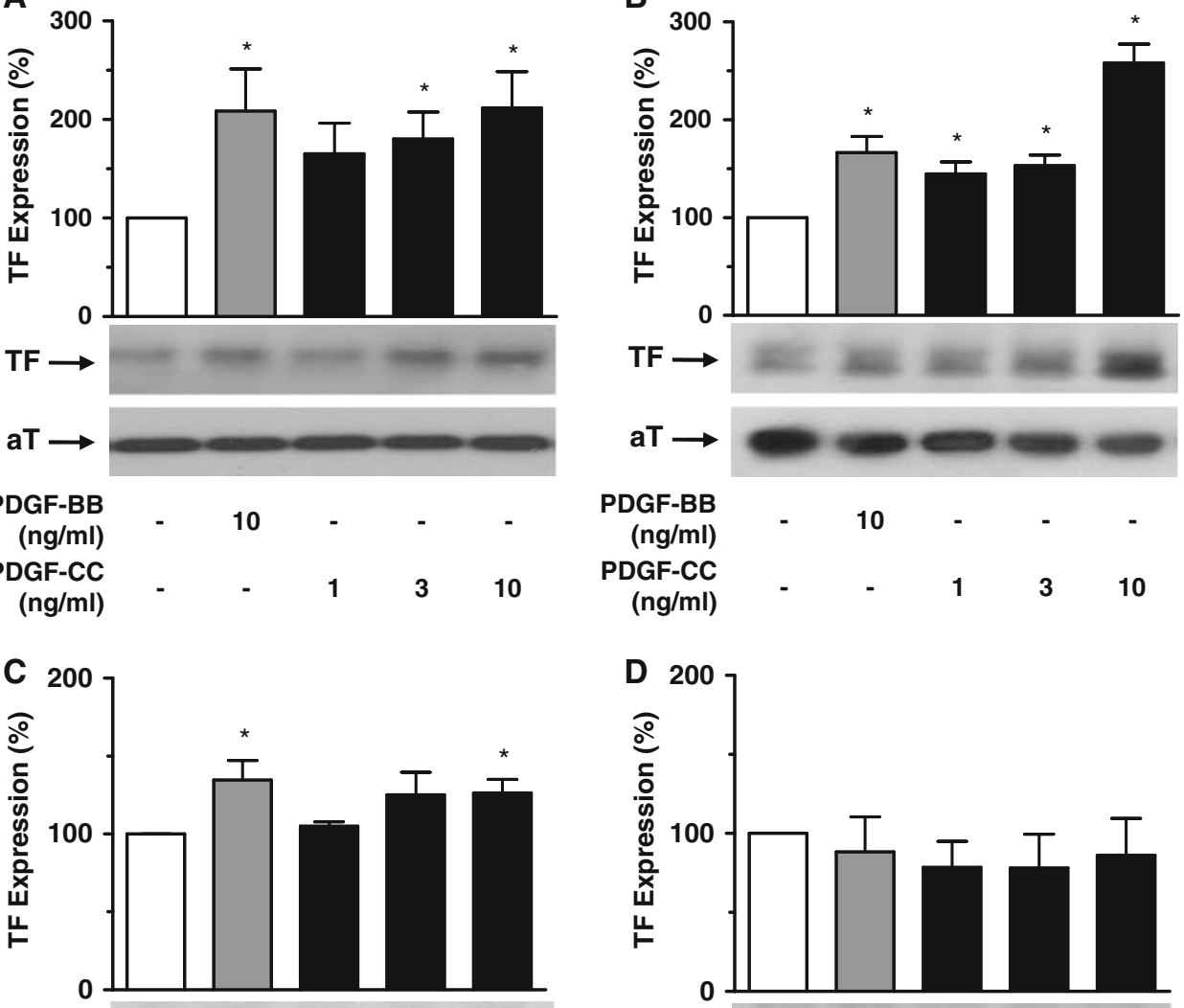

$\mathrm{TF} \rightarrow$

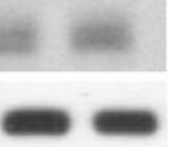

aT $\rightarrow$

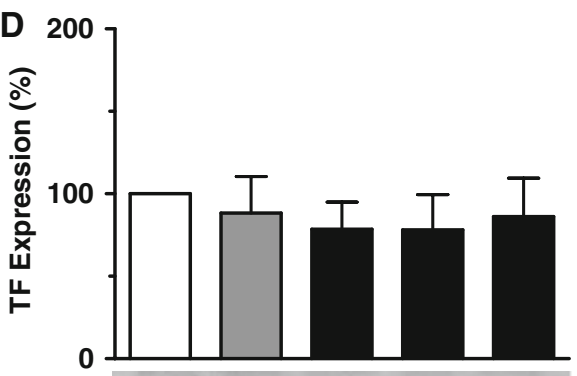

$\mathrm{TF} \rightarrow$

aT -

PDGF-BB

(ng/ml)

PDGF-CC

(ng/ml) (ng/ml)

PDGF-CC

(ng/ml)
3
10 $\rightarrow$

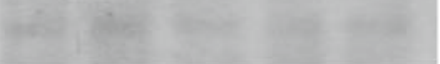

$-10$

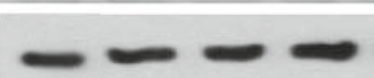

To control for toxic effects, cells were treated with PDGFCC, PDGF-BB, or PDGF-AA for $5 \mathrm{~h}$, and cell death was assessed by LDH release. No significant increase in LDH release was observed for any cell type and any concentration of PDGF used ( $n=4-15 ; P=\mathrm{NS}$; data not shown).

\section{PDGF-CC induces TF mRNA expression}

Real-time PCR revealed that PDGF-CC (0.1-10 ng/mL) induced TF mRNA in THP-1 cells in a concentrationdependent manner with a maximal effect occurring at $10 \mathrm{ng} / \mathrm{mL}$ (3.6-fold vs. control; $n=6, P<0.05$; Fig. 3).

\section{PDGF-CC induces TF via ERK activation}

To assess whether PDGF-CC activates MAP kinases, THP-1 cells were examined at different time points after PDGF-CC stimulation. ERK was transiently activated by

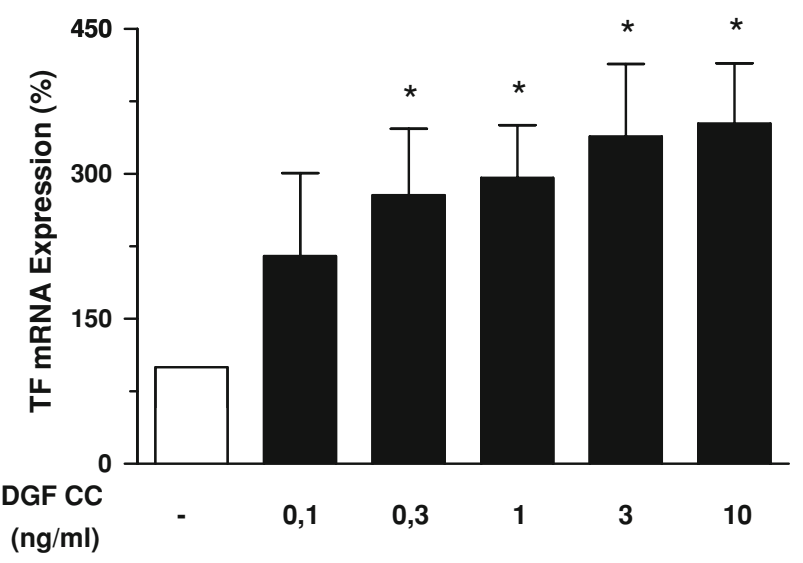

Fig. 3 PDGF-CC induced TF mRNA in THP-1 cells. Values are indicated as percent of control and representative of six different experiments; all blots are normalized to L28 mRNA expression; $* P<0.05$ versus control 
A
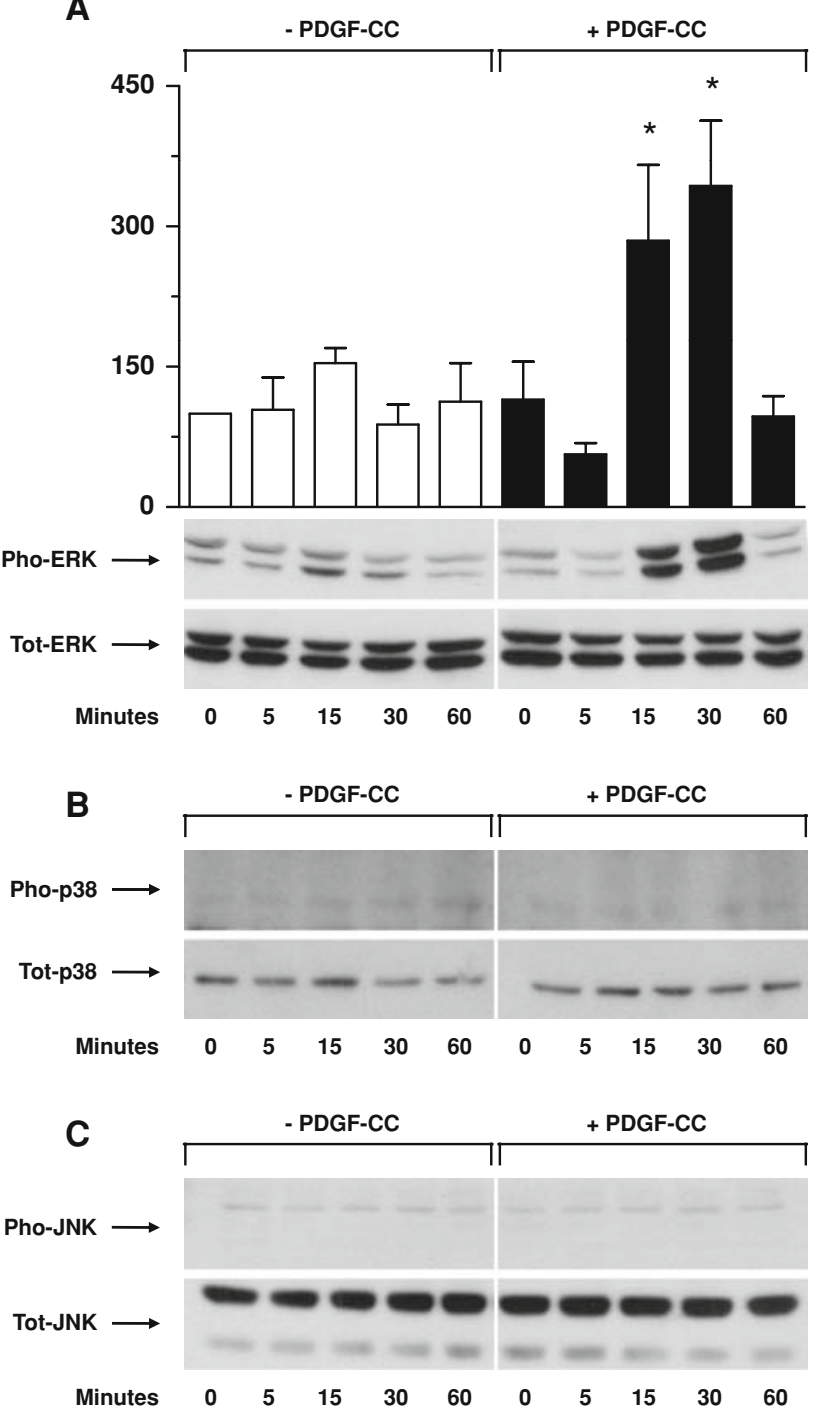

Fig. 4 PDGF-CC induced a transient activation of ERK (a) in THP-1 cells. No change in p38 (b) and JNK (c) phosphorylation occurred. Total (Tot) levels of ERK, p38, and JNK remained unaltered. Values are representative of at least three different experiments

PDGF-CC $(10 \mathrm{ng} / \mathrm{mL} ; n=3, P<0.05$; Fig. 4a), with maximal activation after 15 and $30 \mathrm{~min}$. In contrast, phosphorylation of p38 and JNK remained unaffected as compared to control ( $n=3, P=$ NS; Fig. $4 \mathrm{~b}, \mathrm{c})$. Total expression of ERK, p38, and JNK remained unaltered at all time points examined ( $n=3$; Fig. 4). To confirm a role for ERK activation in PDGF-CC induced TF expression, the effect of MAP kinase inhibitors on TF induction was examined. PD98059 $\left(3 \times 10^{-7}\right.$ to $\left.3 \times 10^{-6} \mathrm{~mol} / \mathrm{L}\right)$, a specific inhibitor of ERK phosphorylation, inhibited PDGF-CC induced TF expression in a concentrationdependent manner $(n=6, P<0.05$; Fig. 5a). In contrast, SB203580 $\left(10^{-6}\right.$ to $\left.10^{-5} \mathrm{~mol} / \mathrm{L}\right)$, an inhibitor of $\mathrm{p} 38$ $(n=3, \quad P=\mathrm{NS} ; \quad$ Fig. $5 \mathrm{~b})$ and SP600125 $\left(10^{-7}\right.$ to $\left.10^{-6} \mathrm{~mol} / \mathrm{L}\right)$, an inhibitor of JNK $(n=4, \quad P=\mathrm{NS}$;
Fig. 5c), did not affect PDGF-CC induced TF expression. No cytotoxic effect of either of these drugs was observed at any concentration used ( $n=3, P=\mathrm{NS}$; data not shown).

PDGF-CC induces TF via $\alpha / \beta$ receptor heterodimer activation

THP-I cells were pretreated with PDGF receptor blocking antibodies. The effect of PDGF-BB on TF expression was inhibited by blockade of PDGF receptor $\beta$, but not PDGF receptor $\alpha(n=3, P=\mathrm{NS}$; Fig. 6a). The effect of PDGF-CC on TF expression was inhibited by blockade of PDGF receptor $\alpha(n=3, P<0.05$; Fig. 6b $)$ or PDGF receptor $\beta(n=3, P<0.05$; Fig. $6 \mathrm{~b})$. No cytotoxic effect of either of these agents was observed at any concentration used ( $n=3, P=\mathrm{NS}$; data not shown).

PDGF-CC-induced ERK phosphorylation depends on PDGFR $\alpha / \beta$ activation

Transient activation of ERK by PDGF-CC was reversed by blocking of PDGF receptor $\alpha(n=6, P<0.05$; Fig. $6 c)$ or PDGF receptor $\beta$ ( $n=6, P<0.05$; Fig. $6 \mathrm{c})$.

\section{Discussion}

The PDGF family consists of four members, PDGF-A, PDGF-B, PDGF-C, and PDGF-D [12, 19, 21]. TF, a key mediator in thrombus formation [29], is induced in monocytes and vascular smooth muscle cells by PDGF$\mathrm{BB}$, a well-characterized member of the PDGF family [6, $18,25]$. PDGF-CC, a newly discovered PDGF isoform, is secreted upon platelet activation, and latent PDGF-CC seems to be activated by locally released proteases of the fibrinolytic and coagulation systems, possibly at the site of ongoing thrombosis $[7,10,20]$. However, the prothrombotic potential of PDGF-CC remains poorly characterized. Therefore, this study analyzed for the first time the effect of PDGF-CC on TF expression in human cells. PDGF-CC induced $\mathrm{TF}$ expression in monocytes, microvascular endothelial cells, and vascular smooth muscle cells with a maximal response at $10 \mathrm{ng} / \mathrm{mL}$. This effect occurred at the transcriptional level and was mediated through PDGFR- $\alpha / \beta$ heterodimer-dependent ERK phosphorylation.

Monocytes are present throughout atherosclerotic lesion progression $[15,17]$; moreover, monocytes seem to be the only blood cells capable of synthesizing TF. Hence, the present findings imply that PDGF-CC may modulate thrombus formation and propagation by activating monocytes. Since PDGF-CC is mainly secreted by activated platelets, this effect may be particularly important under conditions of chronic platelet activation; such conditions 

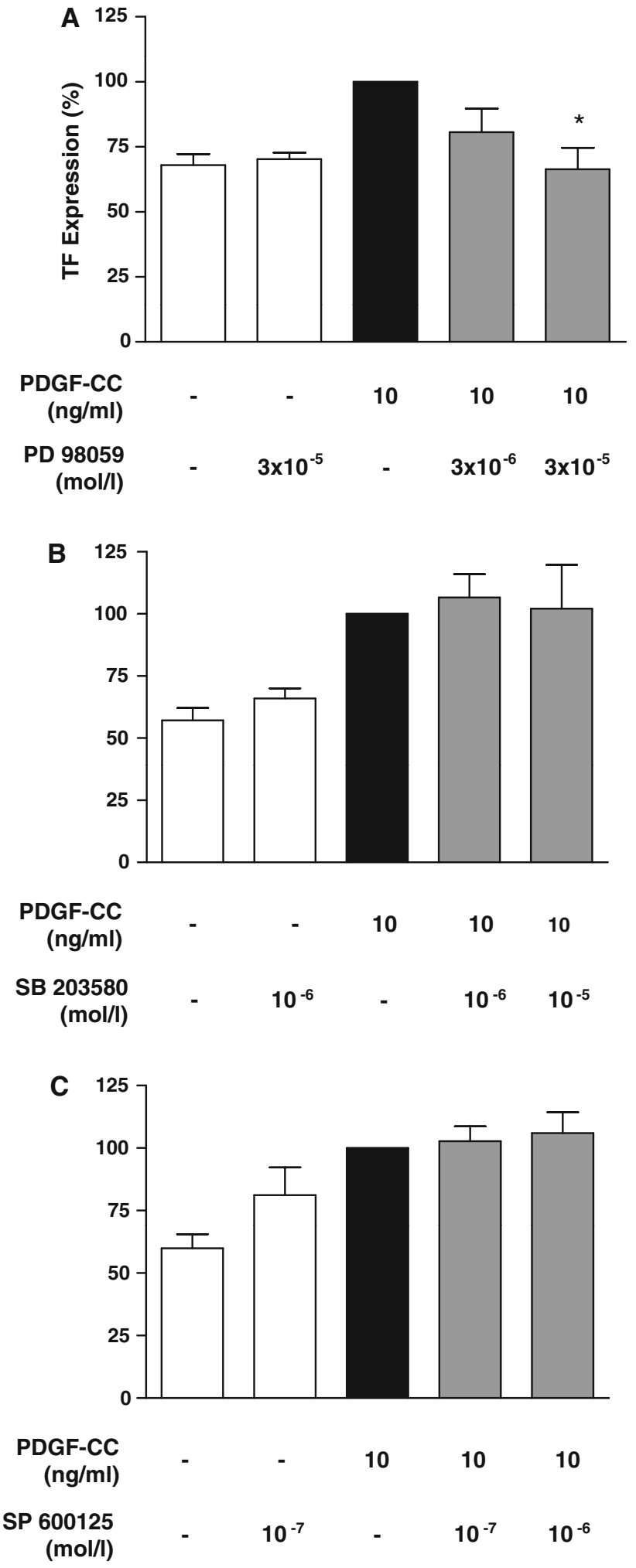

Fig. 5 a The specific inhibitor of ERK activation, PD98059, impaired PDGF-CC induced TF expression in THP-1 cells, while the p38 inhibitor SB203580 (b) and the JNK inhibitor SP600125 (c) did not affect TF. Values are representative of at least three different experiments; all blots are normalized to $\alpha$-tubulin $(a T)$ expression; $* P<0.05$ versus PDGF-CC alone
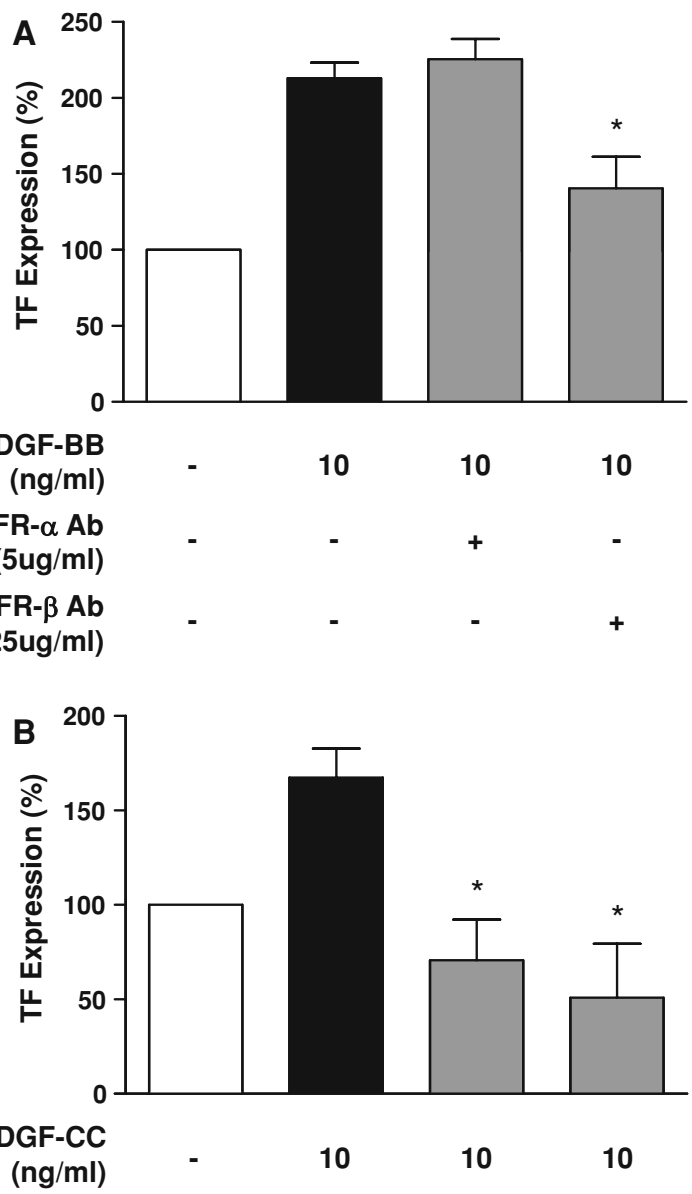

PDGFR- $\alpha$ Ab

$(5 \mathrm{ug} / \mathrm{ml})$

PDGFR- $\beta$ Ab

$(1,25 \mathrm{ug} / \mathrm{ml})$

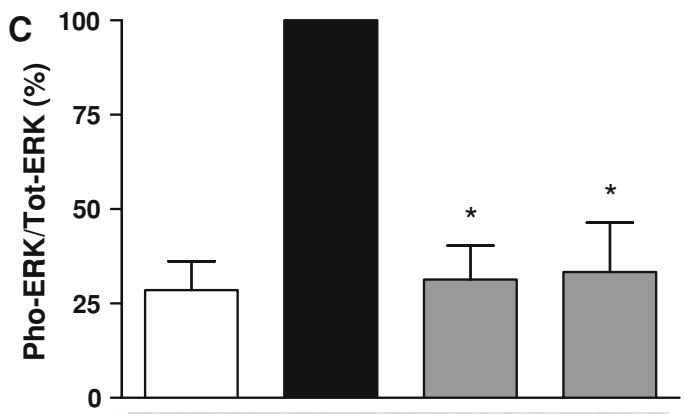

pho ERK

tot ERK

PDGF-CC

(ng/ml)

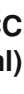

PDGFR- $\alpha$ Ab

(5ug/ml)

PDGFR- $\beta$ Ab

$(1,25 \mathrm{ug} / \mathrm{ml})$ 
4 Fig. 6 a PDGF receptor $\beta$ blocking antibody inhibited TF expression by PDGF-BB, while PDGF receptor $\alpha$ blocking antibody had no effect. ${ }^{*} P<0.05$ versus PDGF-BB alone. b Both PDGF receptor $\alpha$ and receptor $\beta$ blocking antibodies inhibited TF expression by PDGFCC. ${ }^{*} P<0.05$ versus PDGF-CC alone. $\mathrm{c}$ PDGF receptor $\alpha$ blocking antibody and PDGF receptor $\beta$ blocking antibody reversed PDGF-CC induced ERK phosphorylation. $* P<0.05$ versus PDGF-CC alone. Values are representative of at least three different experiments; all blots are normalized to $\alpha$-tubulin $(a T)$ expression and total ERK expression, respectively

have been associated with cardiovascular risk factors such as diabetes mellitus [4], smoking [23] and hyperlipidemia [1].

The absence of PDGF receptors in endothelial cells derived from large vessels is well established [2, 22], whereas microvascular endothelial cells express all PDGF receptors $[16,22]$. In line with this notion, the present study confirms that PDGF-BB and PDGF-CC do not alter TF expression in HAECs even at high concentrations. However, we show that TF expression was concentration-dependently enhanced in HMVECs upon stimulation with either isoform. Notably, in contrast to other vascular cells, the effect of PDGF-CC on TF expression was significantly more potent as compared to that of PDGF-BB in HMVECs. Considering that TF is a candidate marker for the progression of microvascular disease in diabetic patients by its association with microvascular and neurogenic complications [26, 33], and that diabetes mellitus is associated with chronically increased platelet activation [4], the present data suggest that procoagulant activity in patients with ischemic microvascular complications may be triggered by PDGF-CC.

In the vessel wall, TF is constitutively expressed in subendothelial cells such as VSMCs cells leading to rapid initiation of coagulation when the vessel is damaged [29]. PDGF-CC induced TF expression in VSMC in a concentration-dependent manner. The rapid and potent induction of TF by PDGF-CC may be important in those conditions where VSMCs are exposed to activated platelets such as during thrombus formation and in those circumstances where VSMCs migrate such as atherosclerosis and neointimal hyperplasia after vascular intervention [9].

Activated PDGF-CC is a high affinity ligand for PDGFR- $\alpha$ homodimers, while, in contrast to PDGF-BB, it fails to activate PDGFR- $\beta$ homodimers [13]. Similar to PDGF-BB, PDGF-CC can activate PDGFR- $\alpha / \beta$ heterodimers in cells expressing both receptor isoforms [13]. To address the importance of $\alpha$ and $\beta$ PDGF receptors in PDGF-CC-induced TF expression, isotype-matched monoclonal blocking Abs directed against $\alpha$ and $\beta$ PDGF receptors, respectively, were applied [8]. In THP-1 cells, PDGFR- $\beta$ blockade was found to prevent the stimulatory effects of PDGF-BB and PDGF-CC on TF expression. PDGFR- $\alpha$ blockade was ineffective in inhibiting PDGFBB-induced TF expression, whereas TF expression in response to PDGF-CC was prevented. However, no stimulation of TF expression was observed after administration of PDGF-AA, the specific ligand for PDGFR- $\alpha / \alpha$ homodimers. Taken together, these findings indicate an important role of PDGFR-a/ $\beta$ signaling in mediating prothrombotic actions, which has, until now, only been attributed to the PDGFR- $\beta / \beta$ homodimer. Moreover, our data support the conclusion that PDGFR- $\alpha / \alpha$ homodimer signaling is not required for the prothrombotic effects of PDGFs in vascular cells, which supports previously published data $[12,14,19]$.

MAP kinase activation is a key element in regulating TF transcription in response to many stimuli [29]. It is well established that both PDGF-BB induced chemotaxis and TF induction depend on activation of ERK [5, 18, 31, 32]. In the present study, rapid and transient activation of ERK was observed after stimulation by PDGF-CC, whereas JNK and p38 were not affected. Consistent with MAP kinase activation, the increase in TF protein expression by PDGF$\mathrm{CC}$ was preceded by an enhanced TF mRNA expression. Inhibition of MAP kinases by specific inhibitors confirmed that PDCF-CC-induced TF expression was strictly ERKdependent; moreover, PDGFR- $\alpha$ and PDGFR- $\beta$ blockade prevented PDGF-CC-induced ERK phosphorylation, which is consistent with PDGFR- $\alpha / \beta$-dependent signaling. In line with this notion, previous studies have described that the downstream signaling profile of PDGFR- $\beta$ is largely ERKdependent [24], whereas the PDGFR- $\alpha / \alpha$ homodimer may also be able to induce JNK in several cell lines [24].

In conclusion, these data represent the first evidence that PDGF-CC, a newly discovered member of the PDGF family, exerts prothrombotic actions via PDGFR-a/ $\beta$ signaling resulting in ERK-dependent induction of TF expression and activity. The ability of PDGF-CC to stimulate TF expression not only in monocytes, but also in microvascular endothelial cells suggests that it is involved in thrombotic microvascular complications. Hence, a better understanding of the action of PDGF-CC may help refine strategies to prevent microvascular dysfunction. Further, PDGF-CC may be relevant for VSMC migration in conditions such as neointimal hyperplasia after vascular intervention.

Acknowledgment This study was supported by the Swiss National Science Foundation (grant no. 3200B0-113328/1 to FCT and grant no. 3100-068118.02/1 to TFL), Bonizzi-Theler Foundation, Velux Foundation, Wolfermann Nägeli Foundation, and Swiss Heart Foundation.

\section{References}

1. Badimon JJ, Badimon L, Turitto VT, Fuster V (1991) Platelet deposition at high shear rates is enhanced by high plasma cholesterol levels. In vivo study in the rabbit model. Arterioscler Thromb 11:395 
2. Bar RS, Boes M, Booth BA, Dake BL, Henley S, Hart MN (1989) The effects of platelet-derived growth factor in cultured microvessel endothelial cells. Endocrinology 124:1841

3. Bowen-Pope DF, Hart CE, Seifert RA (1989) Sera and conditioned media contain different isoforms of platelet-derived growth factor (PDGF) which bind to different classes of PDGF receptor. J Biol Chem 264:2502

4. Carr ME (2001) Diabetes mellitus: a hypercoagulable state. J Diabetes Complicat 15:44

5. Cospedal R, Abedi H, Zachary I (1999) Platelet-derived growth factor-BB (PDGF-BB) regulation of migration and focal adhesion kinase phosphorylation in rabbit aortic vascular smooth muscle cells: roles of phosphatidylinositol 3-kinase and mitogen-activated protein kinases. Cardiovasc Res 41:708

6. Ernofsson M, Siegbahn A (1996) Platelet-derived growth factorBB and monocyte chemotactic protein-1 induce human peripheral blood monocytes to express tissue factor. Thromb Res 83:307

7. Fang L, Yan Y, Komuves LG, Yonkovich S, Sullivan CM, Stringer B, Galbraith S, Lokker NA, Hwang SS, Nurden P, Phillips DR, Giese NA (2004) PDGF C is a selective alpha platelet-derived growth factor receptor agonist that is highly expressed in platelet alpha granules and vascular smooth muscle. Arterioscler Thromb Vasc Biol 24:787

8. Faraone D, Aguzzi MS, Ragone G, Russo K, Capogrossi MC, Facchiano A (2006) Heterodimerization of FGF-receptor 1 and PDGF-receptor-alpha: a novel mechanism underlying the inhibitory effect of PDGF-BB on FGF-2 in human cells. Blood 107:1896

9. Ferns GA, Avades TY (2000) The mechanisms of coronary restenosis: insights from experimental models. Int J Exp Pathol $81: 63$

10. Fredriksson L, Li H, Fieber C, Li X, Eriksson U (2004) Tissue plasminogen activator is a potent activator of PDGF-CC. EMBO J 23:3793

11. Gebhard C, Stampfli SF, Gebhard CE, Akhmedov A, Breitenstein A, Camici GG, Holy EW, Luscher TF, Tanner FC (2009) Guggulsterone, an anti-inflammatory phytosterol, inhibits tissue factor and arterial thrombosis. Basic Res Cardiol 104:285

12. Giese NA, Marijianowski MM, McCook O, Hancock A, Ramakrishnan V, Fretto LJ, Chen C, Kelly AB, Koziol JA, Wilcox JN, Hanson SR (1999) The role of alpha and beta platelet-derived growth factor receptor in the vascular response to injury in nonhuman primates. Arterioscler Thromb Vasc Biol 19:900

13. Gilbertson DG, Duff ME, West JW, Kelly JD, Sheppard PO, Hofstrand PD, Gao Z, Shoemaker K, Bukowski TR, Moore M, Feldhaus AL, Humes JM, Palmer TE, Hart CE (2001) Plateletderived growth factor $\mathrm{C}$ (PDGF-C), a novel growth factor that binds to PDGF alpha and beta receptor. J Biol Chem 276:27406

14. Heldin CH, Westermark B (1999) Mechanism of action and in vivo role of platelet-derived growth factor. Physiol Rev 79:1283

15. Holvoet P, Collen D (1997) Thrombosis and atherosclerosis. Curr Opin Lipidol 8:320

16. Inaba T, Shimano H, Gotoda T, Harada K, Shimada M, Ohsuga J, Watanabe Y, Kawamura M, Yazaki Y, Yamada N (1993) Expression of platelet-derived growth factor beta receptor on human monocyte-derived macrophages and effects of plateletderived growth factor BB dimer on the cellular function. J Biol Chem 268:24353

17. Kalsch T, Elmas E, Nguyen XD, Suvajac N, Kluter H, Borggrefe M, Dempfle CE (2007) Endotoxin-induced effects on platelets and monocytes in an in vivo model of inflammation. Basic Res Cardiol 102:460

18. Kamimura M, Bea F, Akizawa T, Katus HA, Kreuzer J, Viedt C (2004) Platelet-derived growth factor induces tissue factor expression in vascular smooth muscle cells via activation of Egr1. Hypertension 44:944
19. Kozaki K, Kaminski WE, Tang J, Hollenbach S, Lindahl P, Sullivan C, Yu JC, Abe K, Martin PJ, Ross R, Betsholtz C, Giese NA, Raines EW (2002) Blockade of platelet-derived growth factor or its receptors transiently delays but does not prevent fibrous cap formation in ApoE null mice. Am J Pathol $161: 1395$

20. Li X, Ponten A, Aase K, Karlsson L, Abramsson A, Uutela M, Backstrom G, Hellstrom M, Bostrom H, Li H, Soriano P, Betsholtz C, Heldin CH, Alitalo K, Ostman A, Eriksson U (2000) PDGF-C is a new protease-activated ligand for the PDGF alphareceptor. Nat Cell Biol 2:302

21. Lin ZH, Fukuda N, Suzuki R, Takagi H, Ikeda Y, Saito S, Matsumoto K, Kanmatsuse K, Mugishima H (2004) Adenovirusencoded hammerhead ribozyme to PDGF A-chain mRNA inhibits neointima formation after arterial injury. $\mathrm{J}$ Vasc Res 41:305

22. Marx M, Perlmutter RA, Madri JA (1994) Modulation of plateletderived growth factor receptor expression in microvascular endothelial cells during in vitro angiogenesis. J Clin Invest 93:131

23. Murray JJ, Nowak J, Oates JA, FitzGerald GA (1990) Plateletvessel wall interactions in individuals who smoke cigarettes. Adv Exp Med Biol 273:189

24. Reigstad LJ, Sande HM, Fluge O, Bruland O, Muga A, Varhaug JE, Martinez A, Lillehaug JR (2003) Platelet-derived growth factor (PDGF)-C, a PDGF family member with a vascular endothelial growth factor-like structure. J Biol Chem 278:17114

25. Schecter AD, Giesen PL, Taby O, Rosenfield CL, Rossikhina M, Fyfe BS, Kohtz DS, Fallon JT, Nemerson Y, Taubman MB (1997) Tissue factor expression in human arterial smooth muscle cells. TF is present in three cellular pools after growth factor stimulation. J Clin Invest 100:2276

26. Sommeijer DW, Hansen HR, van OR, Hamulyak K, van Zanten AP, Meesters E, Spronk HM, ten CH (2006) Soluble tissue factor is a candidate marker for progression of microvascular disease in patients with Type 2 diabetes. J Thromb Haemost 4:574

27. Stahli BE, Camici GG, Steffel J, Akhmedov A, Shojaati K, Graber M, Luscher TF, Tanner FC (2006) Paclitaxel enhances thrombin-induced endothelial tissue factor expression via c-Jun terminal NH2 kinase activation. Circ Res 99:149

28. Steffel J, Akhmedov A, Greutert H, Luscher TF, Tanner FC (2005) Histamine induces tissue factor expression: implications for acute coronary syndromes. Circulation 112:341

29. Steffel J, Luscher TF, Tanner FC (2006) Tissue factor in cardiovascular diseases: molecular mechanisms and clinical implications. Circulation 113:722

30. Uutela M, Lauren J, Bergsten E, Li X, Horelli-Kuitunen N, Eriksson U, Alitalo K (2001) Chromosomal location, exon structure, and vascular expression patterns of the human PDGFC and PDGFC genes. Circulation 103:2242

31. Xuereb JM, Sie P, Boneu B, Constans J (2000) Inhibition of tissue factor synthesis by disruption of ERK kinases and PKC signaling pathways in human vascular SMCs. Thromb Haemost $84: 129$

32. Xuereb JM, Sie P, Boneu B, Constans J (1997) Up-regulation of tissue factor expression by platelet-derived growth factor in human vascular smooth muscle cells in culture-role of mitogenactivated protein kinase and effects of intracellular cyclic AMP. Thromb Haemost 78:1520

33. Zumbach M, Hofmann M, Borcea V, Luther T, Kotzsch M, Muller M, Hergesell O, Andrassy K, Ritz E, Ziegler R, Wahl P, Nawroth PP (1997) Tissue factor antigen is elevated in patients with microvascular complications of diabetes mellitus. Exp Clin Endocrinol Diabetes 105:206 